This document is the accepted manuscript version of the following article:

Voumard, M., Venturel1i, L., Borgatta, M., Croxatto, A., Kasas, S., Dietler, G., ... von Gunten, U. (2020). Adaptation of Pseudomonas aeruginosa to constant sub-

inhibitory concentrations of quaternary ammonium compounds. Environmental science:

water Research and Technology, 6(4), 1139-1152. https://doi.org/10.1039/C9EW01056D

\title{
Title: Adaptation of Pseudomonas aeruginosa to constant sub-inhibitory concentrations of quaternary ammonium compounds
}

Running title: Adaptation of $P$. aeruginosa to QACs

Authors: Margaux Voumarda; Leonardo Venturellib; Myriam Borgattac; Antony

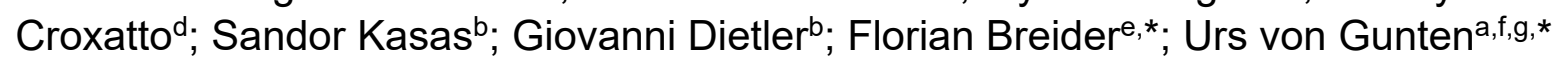
Affiliations:

a Laboratory for Water Quality and Treatment, IIE, ENAC, Ecole Polytechnique Fédérale de Lausanne - EPFL, Switzerland

${ }^{b}$ Laboratory of Physics of Living Matter, IPHYS, SB, Ecole Polytechnique Fédérale de Lausanne - EPFL, Switzerland

${ }^{\mathrm{c}}$ Center for Primary Care and Public Health (Unisanté), University of Lausanne, Epalinges-Lausanne, Switzerland

${ }^{d}$ Institute of Microbiology, Lausanne University Hospital and Lausanne University, Switzerland

${ }^{e}$ Central Environmental Laboratory, IIE, ENAC, Ecole Polytechnique Fédérale de Lausanne - EPFL, Switzerland

${ }^{f}$ Eawag, Swiss Federal Institute of Aquatic Science and Technology - Dübendorf, Switzerland

g Institute of Biogeochemistry and Pollutant Dynamics, ETH Zurich, 8092 Zürich, Switzerland

*Corresponding authors: urs.vongunten@eawag.ch; florian.breider@epfl.ch

Keywords: $P$. aeruginosa, quaternary ammonium compounds, resistance, AFM, membrane, antibiotics, wastewater 


\section{Abstract}

2 Quaternary ammonium compounds (QACs) are widely used in consumer products for

3 disinfection purposes. QACs are frequently detected in aquatic systems at sub-

4 inhibitory concentrations and were found to affect the development of antimicrobial

5 resistance if bacteria are exposed to increasing concentrations. However, the effect of

6 a constant sub-inhibitory concentration on the development of bacterial resistance is unknown. A constant exposure to $88 \%$ of the minimum inhibitory concentration (MIC) of benzalkonium chloride (BAC) led to an increase of the MIC of $P$. aeruginosa. It increased from $80 \mathrm{mg} \mathrm{l}^{-1}$ to $150 \mathrm{mg} \mathrm{l}^{-1}$ after 10 cycles of exposure and remained stable after removal of BAC. When exposed to cetyltrimethyl ammonium chloride (CTMA), $P$. aeruginosa's MIC increased from $110 \mathrm{mg} \mathrm{l}^{-1}$ to $160 \mathrm{mg} \mathrm{l}^{-1}$ after 10 cycles of exposure and decreased to $120 \mathrm{mg} \mathrm{l}^{-1}$ after removal of CTMA. Additionally, cross-resistance between the QACs was observed. When exposed to BAC, the MIC for CTMA increased from $110 \mathrm{mg} \mathrm{l}^{-1}$ to $200 \mathrm{mg} \mathrm{l}^{-1}$, and when exposed to CTMA, the MIC for BAC increased from $80 \mathrm{mg} \mathrm{l}^{-1}$ to $160 \mathrm{mg} \mathrm{l}^{-1}$. In contrast, the susceptibility to 16 antibiotics was not significantly affected by exposure to QACs. Finally, analyses of the membranes' nanomechanical properties of $P$. aeruginosa with atomic force microscopy (AFM) showed increases in cell roughness, adhesion and stiffness after treatment with CTMA. Since sub-inhibitory concentrations of QACs can be detected in (technical) aquatic systems including sediments, this may lead to a dissemination of bacteria with higher QAC resistance in the environment. 


\section{Introduction}

Quaternary ammonium compounds (QACs) are widely used disinfection agents in industrial, medical and household environments $(1,2)$. Benzalkonium chloride (BAC, Figure $1 \mathrm{~A}$ ), a mixture of alkyl dimethyl benzylammonium chlorides, is among the most common QACs found in many consumer, industrial and medical products (3-5). Another widely used QAC is cetyltrimethyl ammonium chloride (CTMA; also known as cetrimonium chloride, Figure 1B). In the clinical context, high loads of QACs are used for the disinfection and cleaning of surfaces and medical instruments (6). The majority of the QACs is discharged to wastewaters (7-11), where they are further diluted and become micropollutants (12). QACs are known to have a poor biodegradability and to persist in waters (13-18). In hospital wastewaters, their concentrations have been measured in the $\mathrm{mg} \mathrm{l}^{-1}$ range (19-21), which is in the sub-inhibitory range for several bacteria such as Pseudomonas aeruginosa ( $P$. aeruginosa) $(19,20)$ In municipal wastewaters, where the dilution effect is bigger, concentrations were measured in the $\mu \mathrm{I} \mathrm{I}^{-1}$ range $(13,21)$. Concentrations of QACs in the $\mathrm{ng} \mathrm{l}^{-1}$ to the $\mu \mathrm{g} \mathrm{I}^{-1}$ have been detected in surface water [13], [19]. In soils and sediments, relatively high concentrations of QACs were also found, the sorption of QAC being high and also highly dependent on their structure (22). As desorption was also observed $(22,23)$, local increases of concentrations of QACs are also possible in surface waters.

Low concentrations of QACs can lead to a selection pressure on microorganisms' populations, that may yield to more QAC-resistant populations $(5,24)$. Bacterial populations have been known to adapt to sub-inhibitory concentrations by mechanisms such as modification of cell membrane structure, efflux pump expression and enhancement of biofilm formation $(10,25)$. The mode of action of QACs at low concentrations may differ from the one at higher concentrations and may involve 
multiple processes similar to antibiotics $(10,26)$. Because of these similar mechanisms, cross-resistance towards other antibacterial agents can occur (20,27-29). Previous studies reported different results, either cross-resistance of $P$. aeruginosa to other disinfection agents and antibiotics or an absence of cross-resistance $(28,30-35)$. The different results obtained in these previous studies highlight the need for more information on a potential development of cross-resistance.

The level of resistance of bacteria or the potential for resistance development is linked with intrinsic properties of bacterial species (36). Among the different bacterial species, $P$. aeruginosa is known to be particularly resistant to QACs and to adapt easily to the presence of antibacterial agents (31). Moreover, $P$. aeruginosa is an important nosocomial bacterium, which is present in tap, recreational and surface water and has been involved in many infectious outbreaks (37-40). These characteristics make this species particularly suitable for investigating the effect of constant sub-inhibitory concentrations of QACs and other disinfection agents.

QACs are part of commercial disinfection agents because of their antibacterial properties. QACs have been used for decades as active substances in commercial disinfection agents. Deconex ${ }^{\circledR} 53$ PLUS, is a commercial product containing various disinfectants and a QAC (see below). Deconex ${ }^{\circledR} 53$ PLUS is used for the pre-cleaning and disinfection of medical instruments. Other commercial disinfection agents include recently developed substances other than QACs. Incidin ${ }^{\circledR}$ PLUS, for example contains glucoprotamin as an active substance, which is included in several commonly used surface and instruments disinfection agents in the health care environment $(41,42)$. A tetracycline-resistant strain of $P$. aeruginosa (PAO-LAC ATCC 47085) was found to be more resistant to this product than a non-antibiotic-resistant strain (42). However, no 
studies were found on the potential of this product to promote resistance at subinhibitory concentrations.

To investigate the effects of QACs or other disinfection agents on bacteria, classical methods such as cultivation are commonly used. In addition to classical microbiological methods, atomic force microscopy (AFM) has been successfully applied to investigate and characterize the bacterial morphology related to resistance to antimicrobial compounds at a single-cell level (43-46). Measurements of alive bacteria in physiological conditions is possible with AFM, preventing any changes in the structure of the membrane when imaging the cells. The primary target of QACs is the bacterial membrane and changes in the membranes are suspected to be involved in the resistance mechanisms of $P$. aeruginosa to QACs. Therefore, AFM is likely to reveal potential changes in the membrane morphology as well as changes in the properties of the membrane in real-time (47). The aforementioned methods (classical microbiology and AFM) have been used to determine the effect of BAC exposure of bacteria. Other QACs, including CTMA, have been scarcely investigated. Studies on BAC focused on the development of resistance when exposed to increasing concentrations of the QAC, but the effect of a constant sub-inhibitory concentration of a QAC or glucoprotamin has had little attention (48).

In this study, the consequences of an exposure of $P$. aeruginosa to BAC, CTMA, Deconex ${ }^{\circledR} 53$ PLUS and to glucoprotamin were investigated. More specifically, the evolution of the MIC, cross-resistance with QACs and antibiotic susceptibilities following exposure were studied. Culture-based methods combined with AFM investigations were applied to characterize the properties of $P$. aeruginosa and highlight any potential change in the bacterial membrane. 


\section{Materials and Methods}

\section{Bacterial strains}

Pseudomonas aeruginosa (ATCC ${ }^{\circledR} 27853^{\mathrm{TM}}$ ) was obtained from the ATCC collection. The strain was stored at $-80^{\circ} \mathrm{C}$ using cryoinstant vials (VWR, Switzerland). Stock cultures were recovered from beads prior to each exposure experiment, by plating the beads on Lysogeny Broth Agar (LBA; Sigma-Aldrich, Switzerland) and on Columbia Blood Agar (Sigma-Aldrich, Switzerland). Colonies from these stock cultures were picked and dissolved in Mueller-Hinton broth (MHB; Sigma-Aldrich, Switzerland) to prepare overnight cultures. Overnight cultures were prepared by incubating the tubes at $37^{\circ} \mathrm{C}$ and $220 \mathrm{rpm}$ for 12 to 18 hours.

\section{Disinfection agents}

The disinfection agents used in this study were two QACs, benzalkonium chloride (BAC, CAS 63449-2) and cetyltrimethyl ammonium chloride (CTMA, CAS 112-02-7) and two one commercial products, Deconex ${ }^{\circledR} 53$ PLUS and Incidin ${ }^{\circledR}$ PLUS. BAC (Sigma-Aldrich, Switzerland) was composed of $70 \%$ benzyldimethyldodecyl ammonium chloride and $30 \%$ benzyldimethyltetradecyl ammonium chloride. The concentration of the product was $\geq 95 \%$ and was of the highest purity available. CTMA (Sigma-Aldrich, Switzerland) had a concentration of 25 wt. \% in $\mathrm{H}_{2} \mathrm{O}$ with the highest purity available. Deconex ${ }^{\circledR} 53$ PLUS (Ecolab Helathcare, Switzerland) contains $9.4 \%$ of the active substances ( $3.8 \mathrm{~g}$ alkyl propylene diamine guanidinium diacetate and 5.6 g N,N-didecyl- $N$-methyl-poly(oxyethyl)ammonium propionate per $100 \mathrm{~g}$ of product). Incidin ${ }^{\circledR}$ PLUS (Ecolab Healthcare, Switzerland) contained $26 \%$ of glucoprotamin as the active substance. Stock solutions of $10,000 \mathrm{mg} \mathrm{l}^{-1}$ of the different antibacterial agents were prepared in Mueller Hinton Broth (MHB). The MHB was sterilized by 
autoclaving before the addition of the QACs or the disinfection agents and the stock solution (MHB and disinfection agent) was filtered by $0.2 \mu \mathrm{m}$ filters (Filtropur S $0.2 \mathrm{~S}$; Sarstedt, Switzerland). The filter-sterilized solutions were then further diluted with in autoclaved MHB to the concentrations of interest for the experiments (MIC determination and repeated exposure). The stock solutions were kept at room temperature and used within a week.

\section{Determination of MICs}

MICs were determined with broth microdilutions following the protocol by Wiegand et al. (2008) (49). Bacterial suspensions were prepared by overnight culture, two to three colonies were diluted in $10 \mathrm{ml}$ of autoclaved MHB and incubated during 12 to 18 hours at $37^{\circ} \mathrm{C}$ and $220 \mathrm{rpm}$. The overnight cultures were diluted to achieve an optical density of 0.12 at $600 \mathrm{~nm}(\mathrm{OD} 600)$ with an optical path length of $1 \mathrm{~cm}$, which was determined to correspond to a concentration of (1-2) $\times 10^{8} \mathrm{CFU} \mathrm{ml}^{-1}$ (colony forming units per ml). This solution was then diluted 1:100 to reach a final concentration of $(1-2) \times 10^{6} \mathrm{CFU}$ $\mathrm{ml}^{-1}$.

The 10 first rows of a sterile 96-well microplate (Nunclon ${ }^{\mathrm{TM}}$ Delta Surface, Thermo Scientific, Switzerland) were filled with $50 \mu \mathrm{l}$ of increasing concentrations of antibacterial solutions. The eleventh column was filled with $50 \mu \mathrm{l}$ of MHB and $50 \mu \mathrm{l}$ of bacterial suspension (growth control) and the twelfth with $100 \mu \mathrm{l}$ of a sterile control. Each well of the antibacterial testing and the growth control were inoculated with $50 \mu \mathrm{l}$ of the bacterial suspension. The microplate was incubated at $37^{\circ} \mathrm{C}$ for $16-20$ hours. The concentrations used for the MIC determination are available in the Supporting Information (Table S1, ESI). After incubation, growth was assessed by turbidity or sediments in the wells. The MIC is defined as the lowest concentration of the antibacterial agent that inhibits visible growth $(49,50)$. 


\section{Repeated exposure to a sub-inhibitory concentration of a disinfection agent}

Figure 2 summarizes the exposure experiments carried out with $P$. aeruginosa. Tubes containing $10 \mathrm{ml}$ of sub-inhibitory concentrations of BAC, CTMA, Deconex ${ }^{\circledR} 53$ PLUS or Incidin ${ }^{\circledR}$ PLUS were inoculated with $100 \mu$ l of an overnight culture of $P$. aeruginosa diluted to obtain a final concentration of $10^{6} \mathrm{CFU} \mathrm{ml}{ }^{-1}$ in the tube at the beginning of the cycle. Concentrations of CTMA and BAC were set at 86 and $88 \%$ of the MIC, at $87 \%$ of the MIC for Deconex ${ }^{\circledR} 53$ PLUS and at $88 \%$ of MIC for Incidin ${ }^{\circledR}$ PLUS, to remain in the sub-inhibitory range while still having a high selective pressure. For BAC, an additional exposure concentration of $50 \%$ of the MIC was tested. For the QACs, one exposure cycle consisted of a 48 hours' incubation at $37^{\circ} \mathrm{C}$ and $220 \mathrm{rpm}$. After 48 hours, the MIC was determined and the bacterial suspension was used to inoculate a new series of tubes with the same sub-inhibitory concentration. A purity check was added by plating $50 \mu \mathrm{l}$ of the bacterial suspension on plate count agar (PCA; SigmaAldrich, Switzerland). This was repeated to reach 10 cycles. Samples were cryopreserved using cryoinstant vials after 5 and 10 cycles of exposure. Two controls were added, one by cycling the bacteria in absence of the disinfection agent in the growth medium $(\mathrm{MHB})$ and a negative control with the growth medium only. A slightly different protocol was used for the exposure to Deconex ${ }^{\circledR} 53$ PLUS and to Incidin ${ }^{\circledR}$ PLUS, one exposure cycle was defined as 24 hours and the total experiment lasted 10 cycles of exposure for Deconex ${ }^{\circledR} 53$ PLUS and 15 for Incidin ${ }^{\circledR}$ PLUS 15 cycles of exposure followed by 5 cycles of stability. The MICs were determined every five cycles of exposure and the samples were cryopreserved at the same time.

\section{Stability}

To investigate if the effects of the exposure to disinfection agents remains stable in absence of the disinfection agent from the medium, five cycles in disinfection agent- 
170 free MHB were added at the end of the total exposure (10 cycles). As in the exposure experiments, cycles of $48 \mathrm{~h}$ were carried out and a purity check was added after each cycle. The MIC was determined after each cycle, the antibiotic susceptibility profile and the cross-resistance was assessed at the end of the three cycles. For Deconex ${ }^{\circledR} 53$ PLUS and Incidin ${ }^{\circledR}$ PLUS, cycles of $24 \mathrm{~h}$ were added for the stability experiments.

\section{Determination of the antibiotic susceptibility profiles}

10 antibiotics, which are known to be effective against $P$. aeruginosa, were selected according to the European Committee on Antimicrobial Susceptibility Testing (EUCAST) recommendations (51). The selected antibiotics belong to the classes of aminoglycosides (tobramycin $10 \mu \mathrm{g}$; amikacin $30 \mu \mathrm{g}$; gentamycin $10 \mu \mathrm{g}$ ), cephalosporin (cefepime $30 \mu \mathrm{g}$; ceftazidime $10 \mu \mathrm{g}$ ), fluoroquinolones (ciprofloxacin 5 $\mu \mathrm{g}$; levofloxacin $5 \mu \mathrm{g}$ ); penicillin (piperacillin-tazobactam $36 \mu \mathrm{g}$ ) and carbapenem (imipenem $10 \mu \mathrm{g}$; meropenem $10 \mu \mathrm{g}$ ). In addition, 6 antibiotics, to which $P$. aeruginosa is naturally resistant, were also tested. These antibiotics belong to the classes of cephalosporin (cefoxitine $30 \mu \mathrm{g}$; cefuroxime $30 \mu \mathrm{g}$ ), penicillin (ampicillin $10 \mu \mathrm{g}$ ), sulfonamide (co-trimoxazole $25 \mu \mathrm{g}$ ), nitrofuran (nitrofurantroin $100 \mu \mathrm{g}$ ) and tetracycline (minocycline $10 \mu \mathrm{g}$ ). They were used in the form of antimicrobial susceptibility disks (Thermo Scientific ${ }^{\mathrm{TM}}$ Oxoid ${ }^{\mathrm{TM}}$ Gentamycin Antimicrobial Susceptibility Disks, Thermo Scientific, Switzerland). The disks were stored at $-20^{\circ} \mathrm{C}$, according to the manufacturer's instructions.

The antibiotic susceptibility profiles were determined using the disc diffusion method after 5 and 10 cycles of exposure, following the EUCAST methodology (51). The bacterial growth was diluted in MHB to reach an OD600 of 0.12 , as in the determination of the MIC. This solution was swabbed on Mueller-Hinton agar plates (MHA plates). Antibiotic discs were then applied to the agar surface using a disc dispenser (Oxoid ${ }^{\mathrm{TM}}$ 
Antimicrobial Susceptibility Disk Dispenser) and the plates were incubated for 24 hours at $37^{\circ} \mathrm{C}$. The inhibition zone diameters (IZD) were recorded using calipers after the incubation period. The IZDs were then compared to the EUCAST database for $P$. aeruginosa (51).

\section{Cross-resistances among QACs}

Susceptibility to the QAC to which the bacterial populations were not exposed was determined to investigate if exposure to one QAC leads to a higher resistance to the other one. The MIC for CTMA was determined after 5 and 10 cycles of exposure to BAC and after the stability period using the broth microdilution method. The MIC for BAC was determined after 5 and 10 cycles of exposure to CTMA and after the stability period using the broth microdilution method.

\section{AFM Imaging}

AFM measurement were performed on the treated cells with approximately $90 \%$ of the MIC during 10 cycles (for CTMA and BAC only). The measurements were performed before the stability period but in absence of the QACs. The bio-mechanical properties of $P$. aeruginosa strains were measured using a JPK NanoWizard 3 AFM (Bruker Nano $\mathrm{GmbH}$, Germany), equipped with a Zeiss TE-100 inverted microscope (Bruker, Germany) in PBS buffer at room temperature $\left(25^{\circ} \mathrm{C}\right)$. The so called "quantitative imaging" mode was used to image the cells to gather both high quality 3D topology and determine mechanical properties, adhesion and stiffness. The scan size of the AFM images was adapted to fit an area with at least 20 cells and 10 areas per samples have been imaged. Typically, a square ranging from $15 \times 15$ to $25 \times 25 \mu \mathrm{m}$ was chosen. Every image consisted of either a $64 \times 64$ or a $128 \times 128$ force-distance $(F / d)$ curve recorded with an indentation dwell-time of 80 milliseconds and a set-point force of 1200 
pN. Specifically, each pixel in the AFM adhesion image has a value of force that is basically the registered minimum in the retrace function of the F/d curve. The adhesion force is a minimum value because it is considered as a pulling force from the cell towards the cantilever, and thus generated from the cell. For these experiments we used $200 \mu \mathrm{m}$-long triangular silicon nitride probes, supplied by pyramidal tips with a nominal radius of $20 \mathrm{~nm}$ (DNP-10 Bruker, Bruker Nano Inc., CA, USA) and a nominal spring constant of $0.06 \mathrm{~N} / \mathrm{m}$. The scanned height was set to $1 \mu \mathrm{m}$, to be able to completely cover the cell height. The bottom glass-modified petri dishes, employed for the AFM experiments, allowed us to strongly improve the stiffness image contrast, due to few orders of magnitude differences between cells (hundreds of $\mathrm{kPa}$ ) and glass (hundreds of MPa) Young's modulus.

\section{AFM Data Processing}

The AFM data were processed using the "JPK Data Processing" software to obtain the values for the adhesion parameters and by applying the Hertz-Sneddon fit it calculates the Young's modulus. A Matlab (MathWorks Inc., CA, USA) script, developed in our laboratory allowed to sharply discriminate and extract the points belonging to the bacteria cells from the background and then use them to plot the final graphs. Briefly, the script analyses each stiffness, adhesion and height image files and it creates a new matrix text file $(64 \times 64$ or $128 \times 128$ points, based on the original image size $)$ made of 0 and 1 , where 0 means background and 1 means cell. The selection process consists of applying a threshold on the height AFM image. The so generated matrix files are then plotted as black and white images to check whether the script worked correctly. Afterwards the matrix files are used as a mask to extract the positive matching points from the stiffness, adhesion and height files. The selected points are finally plotted and averaged using the software OriginPro 2018 (OriginLab Corporation, MA, USA). 
The average roughness was calculated by the "JPK Data Processing" software, which can calculate the average roughness (here named also $\mathrm{Ra}$ ) of a specifically selected cross section from the raw files.

\section{Statistical analyses}

1. MIC evolution upon exposure to disinfection agents

To determine the statistical significance of the results for the evolution of the MIC during exposure to sub-inhibitory QAC concentrations, linear regression analysis was used. The analyses were performed in R using the R package Ime4 (52). To test if the MIC significantly changes over the cycles when exposed to a disinfection agent, measurements taken during the stability period were excluded and a linear regression was performed. The variables of the mixed model were selected using a backward approach; a reduced model missing the variable of interest was compared to the full model by an ANOVA. The p-value was extracted and the variable was considered as having a significant effect on the MIC for p-values $<0.01$.

\section{Stability period and cross-resistance}

To determine the statistical significance of the stability period, dependent t-tests were performed. MIC at the end of the exposure period (after 10 cycles) were compared to values after the three cycles of stability. If significant differences were observed ( $p$ value $<0.01$ ), the MIC after stabilization was compared to the MIC before exposure to assess if the MIC was reversible.

The significance of the cross-resistance values was investigated using dependent and independent t-tests. MICs for one disinfection agent were compared at similar time points after exposure to both disinfection agents and to the control. Differences were considered significant for $p$-values $<0.01$. 
The effects of the exposure to disinfection agents on antibiotic susceptibilities were analyzed using ANOVA on three populations (exposed to CTMA, exposed to BAC and not exposed) after 5 and 10 cycles of exposure and after the stability period. False discovery rate adjustment (Bonferroni) (53) was applied to correct the p-values. For the antibiotics for which the difference was still significant after correction ( $p$-value < 0.01), Tukey's HSD was applied to determine for which pairs the difference was significant. The results were then compared to the EUCAST threshold values for resistance (51).

\section{AFM data}

The effect of the exposure to disinfection agents on the bacterial mechanical properties was analyzed using a one-tail ANOVA on the three populations (exposed to CTMA, exposed to BAC and not exposed). The p-value was considered significant if $<0.05$. To assess the roughness property difference, a non-parametric Mann-Whitney test was applied with a p-value $<0.05$.

\section{Results}

The MIC of $P$. aeruginosa for CTMA was determined by broth microdilutions to be 110 $\mathrm{mg} \mathrm{l}^{-1}$. Based on this result, the sub-inhibitory concentration to which the bacterial populations were exposed was set at $95 \mathrm{mg} \mathrm{l}^{-1}$ ( $86 \%$ of MIC). This concentration is in 
291 the sub-inhibitory range but will also exert a mild selective pressure (24). For $P$. aeruginosa exposed to this sub-inhibitory concentration of CTMA a significant increase of the MIC was observed. Each cycle contributed significantly $(p<0.001)$ to an average increase of the MIC between $5.0 \pm 0.8 \mathrm{mg} \mathrm{l}^{-1}$ (replicate 1), $3.6 \pm 0.9 \mathrm{mg} \mathrm{l}^{-1}$ (replicate 3) and $2.7 \pm 0.7 \mathrm{mg} \mathrm{l}^{-1}$ (replicate 2). After 10 cycles, the MIC reached a value of $150 \pm 10$ $\mathrm{mg} \mathrm{I}^{-1}$ (Figure 3A). Overall the MIC increased by a factor of $1.3-1.45$. In the control experiment (cycling without exposure), no significant changes in the MICs were found (Table S1, ESI).

The stability of the adaptation to CTMA was tested by five additional cycles in absence of CTMA. The MIC was again tested at the end of these cycles and a significantly lower value was found. However, the MIC after this procedure was still significantly higher $\left(127.5 \pm 9.6 \mathrm{mg} \mathrm{l}^{-1}\right)$ than the initial value. The values were at an intermediate level between samples that were non-exposed and exposed to CTMA for 10 cycles (Figure 3A, Table S2, ESI).

$B A C$

The MIC of $P$. aeruginosa for BAC was determined to be $80 \mathrm{mg} \mathrm{l}^{-1}$.

P. aeruginosa was exposed to $40 \mathrm{mg} \mathrm{l}^{-1} \mathrm{BAC}$, which corresponds to $50 \%$ of the MIC (Figure S1, ESI). The effect of exposure on the MIC of the strains was significant but small for replicate 1 , where an average increase of the MIC of $1.36 \pm 0.45 \mathrm{mg} \mathrm{l}^{-1}$ per cycle was observed. The effect of the cycles was not significant and no increase was observed for replicates 2 and 3. After removal of the BAC from the medium, the small increase observed after 10 cycles is no more present and the MIC is back towards the initial value. 
To induce a potentially larger effect, $P$. aeruginosa was exposed to a concentration equal to $88 \%$ of the MIC (70 $\left.\mathrm{mg} \mathrm{l}^{-1}\right)$. When exposed to this concentration of BAC, the MIC increased first to $125 \mathrm{mg} \mathrm{l}^{-1}$ and then to $150 \mathrm{mg} \mathrm{l}^{-1}$ (replicates 1 and 2). For replicate 3 , the MIC increased to $100 \mathrm{mg} \mathrm{l}^{-1}$. Thus, the final observed increase factors were 1.9 (replicates 1 and 2) and 1.25 times the initial MIC (replicate 3, Figure 3B, Table S2, ESI).

The stability of the adaptation to BAC was tested by five additional cycles in absence of BAC. The MIC was again measured after these cycles and the value obtained was similar to the one obtained at the end of the exposure period. Therefore, the MIC values remained at $150 \mathrm{mg} \mathrm{l}^{-1}$ (replicates 1 and 2) and a small decrease was observed for replicate 3, with a MIC at $90 \mathrm{mg} \mathrm{l}^{-1}$ after the stability period.

\subsection{Cross-resistance between the QACs}

Cross-resistance between the QACs was assessed by testing the populations for 5 and 10 cycles of exposure to BAC followed by 5 cycles of stability against CTMA and the CTMA-exposed population against BAC. The results are provided in Table S3 (ESI) and in Figures $5 \mathrm{~A}$ and $\mathrm{B}$. A weak positive correlation was also found between the increase of the MIC for BAC and the increase of the MIC for CTMA when exposed to BAC (Spearman correlation factor of 0.6) (Figure 5A). A stronger positive correlation between the increase of the MIC for exposure to CTMA and the increase of the MIC for BAC when pre-exposed to CTMA was found (Spearman correlation factor of 0.8 ) (Figure 5B).

\subsection{Antibiotic susceptibilities after exposure to QACs}

The effects of the exposure of $P$. aeruginosa to sub-inhibitory QAC concentrations after 5 and 10 cycles on the antibiotic susceptibilities was tested using an analysis of 
variance between the control and the exposed populations followed by a Dunnett posthoc test (Table S4, ESI). From the results of the statistical analyses, after 10 cycles of exposure, significant differences $(p<0.01)$ were observed for amikacin, tobramycin, gentamycin (higher resistance of $P$. aeruginosa), and piperacillin-tazobactam (lower resistance of $P$. aeruginosa) for the strain exposed to CTMA versus the control. Bacteria exposed to BAC exhibited statistical differences for levofloxacin, imipenem and minocycline (lower resistance of $P$. aeruginosa) after 10 cycles of exposure. However, the difference in resistance observed with these antibiotics was insufficient to modify the categorical interpretation (Susceptible /Intermediate /Resistant) according to EUCAST breakpoints. Among the 16 antibiotics tested, $P$. aeruginosa is intrinsically resistant to six of them and being exposed to either BAC or CTMA did not affect this intrinsic resistance.

\subsection{Evolution of the MIC of $P$. aeruginosa for Deconex ${ }^{\circledR} 53$ PLUS with} exposure cycles and stability after removal of the disinfection agent

Figure 4 shows the evolution of the MIC of $P$. aeruginosa for exposure to $140 \mathrm{mg} \mathrm{l}^{-1}$ of Deconex ${ }^{\circledR} 53$ PLUS (13 $\mathrm{mg} \mathrm{l}^{-1}$ active substance), which corresponds to $87 \%$ of the MIC (160 $\mathrm{mg} \mathrm{l}^{-1}, 15 \mathrm{mg} \mathrm{l}^{-1}$ of active substance). The MIC increased to $300 \mathrm{mg} \mathrm{l}^{-1}\left(28 \mathrm{mg} \mathrm{l}^{-1}\right.$ of active substance) for one replicate (replicate 1) and to $266 \mathrm{mg} \mathrm{l}^{-1}\left(25 \mathrm{mg} \mathrm{l}^{-1}\right)$ for two replicates (replicates 2 and 3). Each cycle contributed to an increase of the MIC by an average of $10 \mathrm{mg} \mathrm{l}^{-1}$, independently of the replicate. The control remained at $168 \pm 20$ $\mathrm{mg} \mathrm{l}^{-1}\left(16 \pm 1.8 \mathrm{mg} \mathrm{l}^{-1}\right.$ active substances). After a stability period of 5 cycles in absence of the disinfection agents, the MIC either stayed at the higher value (replicates 1 and 3) or decreased to $212 \mathrm{mg} \mathrm{l}^{-1}$ (replicate 2).

An exposure to Deconex ${ }^{\circledast} 53$ PLUS also led to a decreased susceptibility to both CTMA and BAC (Figures 5C and D). When exposed to Deconex ${ }^{\circledR} 53$ PLUS, the MIC for CTMA 
363 increased to $250 \mathrm{mg} \mathrm{l}^{-1}, 2.25$ times the initial MIC, for replicate 1 , and to $200 \mathrm{mg} \mathrm{l}^{-1}$, 3641.8 times the initial MIC, for replicates 2 and 3 (Figure 5C). The MIC for BAC increased to $140 \mathrm{mg} \mathrm{l}^{-1}, 1.75$ times the initial MIC for replicate 1 and to $100 \mathrm{mg} \mathrm{l}^{-1}, 1.25$ times the initial MIC, for replicates 2 and 3 (Figure 5D).

The increase in the MIC was strongly correlated with increases in the MIC for BAC and CTMA with Spearman correlation factors of 0.94 (for CTMA) and 0.84 (for BAC).

\subsection{Evolution of the MIC of $P$. aeruginosa for Incidin ${ }^{\circledR}$ PLUS with exposure cycles and stability after removal of the disinfection agent}

Exposure to Incidin ${ }^{\circledR}$ PLUS during 15 cycles of 24 hours led to a significant increase of the MIC of $P$. aeruginosa The MIC was determined to be $40 \mathrm{mg} \mathrm{l}^{-1}\left(10 \mathrm{mg} \mathrm{l}^{-1}\right.$ of glucoprotamin) prior to exposure. The concentration of exposure was set at $35 \mathrm{mg} \mathrm{l}^{-1}$ (9 $\mathrm{mg} \mathrm{l}^{-1}$ glucoprotamin; $88 \%$ of the MIC). The MIC reached a maximum of $100 \mathrm{mg} \mathrm{l}^{-1}$ (26 mg l-1 glucoprotamin) after 15 cycles of exposure (Figure 4B, replicate 3), which correspond to an increase of the initial MIC by a factor of 2.5 and each cycle increased the MIC by an average of $3.2 \pm 1.2 \mathrm{mg} \mathrm{l}^{-1}$. An increase to $70 \mathrm{mg} \mathrm{l}^{-1}$ (18 $\mathrm{mg} \mathrm{l}^{-1}$ glucoprotamin) was observed for replicate 3, which corresponds to an increase of the initial MIC by a factor 1.75 and an increase per cycle of $1.73 \pm 0.5 \mathrm{mg} \mathrm{l}^{-1}$. The control (not exposed to Incidin ${ }^{\circledR}$ PLUS) remained at $40 \mathrm{mg} \mathrm{l}^{-1}$ (10 $\mathrm{mg} \mathrm{l}^{-1}$ glucoprotamin) during the cycling period (Figure 4B).

The stability of the adaptation to Incidin ${ }^{\circledR}$ PLUS was investigated by removing the disinfection agent from the growth media during 5 cycles (in this case, of 24 hours). The increases in the MICs were stable and irreversible, remaining at the values obtained at the end of the exposure period. 


\subsection{Antibiotic susceptibilities following exposure to Deconex ${ }^{\circledR} 53$ PLUS and} Incidin ${ }^{\circledR}$ PLUS

The effects of exposure to sub-inhibitory concentrations of Deconex ${ }^{\circledR} 53$ PLUS and of Incidin ${ }^{\circledR}$ PLUS concentrations after 5, 10 and 15 cycles on the antibiotic susceptibilities was tested using an analysis of variance between the control and the exposed populations followed by a Dunnett post-hoc test, similarly to QACs. No differences were observed between the Incidin ${ }^{\circledR}$ PLUS exposed strains and the controls (data not shown).

\subsection{AFM}

The AFM measurements allowed to investigate the mechanical properties of single $P$. aeruginosa cells at the nanometric scale. The main properties that were elucidated by this method are: (1) The roughness of the bacterial outer membrane, (2) the stiffness of the whole bacteria cell and (3) its adhesion properties. The AFM probe (also named cantilever tip) having a diameter of roughly $40 \mathrm{~nm}$, is able to detect and scan very small details of the bacterial surface. The $P$. aeruginosa cells showed an average roughness (Ra) of 30nm (Figure 6A - left) when no QAC exposure occurred. CTMA treatment strongly affected the outer membrane characteristics of $P$. aeruginosa. The measured Ra after exposure to CTMA was around 95nm, on average, with peaks of $200 \mathrm{~nm}$ (Figure 6A - right). When BAC was administered, the average measured Ra was around $75 \mathrm{~nm}$ (Figure 6A - middle). Hence, for both tested QACs the outer membrane roughness significantly changed as a consequence of the positive charge interactions with the membrane components.

Furthermore, the probe indentation on the bacterial cell allowed to obtain a precise measurement of cell stiffness. In addition, the recording of any occurring interaction 
event, of either weak or strong value in between the tip and the protein/lipid matrix of the outer membrane, allowed to obtain roughness and adhesion parameters. Even though, the cantilever tip was not functionalized with any biological molecule (for instance: fibronectin, collagen, concanavalin-A, antibodies, etc.) and the indentation contact time was less than $100 \mathrm{~ms}$, a measurable interaction still remained with an adhesion peaks plotted in Figure 6B. In Figures 6B and C, each point corresponds to a pixel belonging to the whole bacteria population that has been imaged with the AFM (almost 100 cells per treatment in at least 5 different images of $20 \mu \mathrm{m} \times 20 \mu \mathrm{m}$, with a resolution of $128 \times 128$ pixels). For $P$. aeruginosa, the registered average value of adhesion was almost $1.0 \mathrm{nN}$, whereas after the treatment with BAC it dropped to less than the half, specifically $0.4 \mathrm{nN}$ (Figure 6B). Interestingly, the treatment of $P$. aeruginosa with CTMA increased the adhesion properties between the outer membrane and the cantilever tip by almost $50 \%$ compared to the original strain, yielding an average value of $1.5 \mathrm{nN}$. When the adhesion properties after BAC treatment is compared with the CTMA treatment a statistically significant difference (one-tail ANOVA, p-value $<0.05$ ) of more than 3 -fold was found, 0.4 versus $1.5 \mathrm{nN}$, respectively.

In Figure 6C the Young's modulus values distribution is plotted as a parameter to represent the bacterial stiffness. The measured stiffness from the three bacteria populations differed significantly only for the CTMA treated case. The determined value for the investigate P. aeruginosa strain (ATCC 27853) is around $210 \mathrm{kPa}$, which is the same as for the BAC-treated case (almost $210 \mathrm{kPa}$ ). Remarkably, CTMA acted differently again from the BAC counterpart by significantly increasing the bacteria stiffness value by almost a factor of three, up to $610 \mathrm{kPa}$ (one-tail ANOVA, p-value < 0.01). 


\section{Discussion}

2.1. Evolution of the MIC of $\boldsymbol{P}$. aeruginosa for CTMA and BAC with exposure cycles, stability after removal of the disinfection agent and crossresistances between the QACs and with antibiotics

Populations of $P$. aeruginosa were exposed to constant sub-inhibitory concentrations of CTMA and BAC, and adaptation occurred (increase in MIC) when the bacteria were exposed to a concentration of the selected QACs corresponding to approximately $90 \%$ of the MIC. A small increase in the MIC was observed for one replicate (out of three) when $P$. aeruginosa was exposed to $50 \%$ of the MIC. The strength of the selection pressure was important, as in the case of BAC, the adaptation was much stronger with an exposure concentration at $90 \%$ of the MIC compared to an exposure concentration of $50 \%$ of the MIC. However, it cannot be excluded that stronger adaptation may occur for longer exposure periods with $<90 \%$ of the MIC. When exposed to approximately $90 \%$ of the MIC of the selected QACs, the general trend was an increase of the MIC, however, the individual replicates showed different patterns. Previous studies revealed that a long-term exposure to BAC led to a reduction in the community diversity and an increase in the resistant bacteria $(25,54)$. Variability in the adaptation was also observed here, resulting from a low selective pressure. This variability can be the result of either different mechanisms or differences in the speed of adaptation. Exposure of E. coli strains to sub-inhibitory concentrations of BAC led to different phenotypical variants (25) and it is possible that the resulting exposed populations in this study are also comprised of phenotypic variants.

The results showed that an increase was still present at the end of the 10 cycles investigated (Figures 3 and 5). In previous studies it has been shown that an increasing concentration of QACs ultimately reaches a plateau of the MIC (35). It can be 
hypothesized that an exposure to a constant sub-inhibitory concentration of QACs also ultimately leads to a plateau of the MIC.

After removal of the QAC from the growth medium, the MIC for CTMA decreased to similar values prior to the exposure. However, when exposed to BAC, the MIC reached during the exposure period remained stable at the higher level. If the mechanisms are of similar nature, as shown with the experiments on cross-resistance, exposure to CTMA seems to trigger a transient mechanism of adaptation, which is different from BAC. Mechanisms of adaptation or resistance to QACs includes modification of the membrane or expression of efflux pumps $(29,33,54)$. These mechanisms are consistent with a transient change either in the structure of the membrane or in the level of expression of other resistance mechanisms. The differences observed between the two selected QACs might be linked to the composition of the QACs, BAC being a mixture of several quaternary ammonium compounds with different aliphatic chains ranging from 8 to 16 carbon atoms with an aromatic ring (Figure $1 \mathrm{~A}$ ), while CTMA is a single quaternary ammonium compound with one aliphatic chain length (Figure 1B). However, this would need further investigations.

When exposed to CTMA first, $P$. aeruginosa became more resistant to BAC and when exposed to BAC, it became more resistant to CTMA (Figures 5 A and $B$,). This result was demonstrated by a positive correlation score obtained in both cases. This might mean that the mechanisms involved are shared or similar for the two QACs. The nature of the mechanism might rather be the result of phenotypical changes for CTMA, because the increase of the MIC after removal of the QAC was reversible. For the other tested compounds, genotypic changes cannot be excluded. The increased resistance might be linked to morphological changes of the membrane observed by AFM or to the expression of other mechanisms, such as efflux pumps as shown in previous studies 
485 (29). When exposed to a commercial disinfection agent containing QACs, crossresistance was also observed with BAC and CTMA. Strains exposed to Deconex ${ }^{\circledR} 53$ PLUS demonstrated a higher tolerance for CTMA and BAC compared to their control. Similarly, to BAC and CTMA only, the degree of tolerance was strongly correlated with the level of adaptation. The decrease in the susceptibility, when exposed to Deconex ${ }^{\circledR}$ 53 PLUS, was stronger for CTMA, for which a maximum increase in the MIC of up to a factor 1.25 was observed (Figure 5 C). For BAC, it reached a maximum increase of the MIC by a factor 1.8 (Figure 5D).

Cross-resistance with antibiotics was less evident than for QACs. Statistical differences were observed with either increased or decreased resistance to antibiotics. However, the categorical interpretation (S/I/R) according to EUCAST breakpoints were not modified. These results are in accordance with previous studies, in which exposure to BAC or CTMA did not lead to any significant difference in the resistance profile to antibiotics (30-32).

\subsection{Morphological evolution of the bacteria}

AFM investigations revealed some differences in the treated compared the non-treated bacterial cells. The roughness of the cells increased with the treatment, similarly to the results of other studies investigating antibiotics or antimicrobial agents $(46,55,56)$. As QACs are agents targeting the outer membrane of bacteria, this result indicates that even at subinhibitory concentrations, bacterial membranes are affected by QACs. The mechanism of action of QACs is known to be an association of the positively charged quaternary nitrogen with the head groups of acidic-phospholipids of the membrane (57). This interaction decreases the fluidity of the membrane at concentrations close to the MIC (57). Adaptation of $P$. aeruginosa to one QAC was observed to result in changes in the cell surface hydrophobicity and biofilm formation, but also to be the 
cause of changes in the outer membrane proteins and the permeability $(31,33)$. When exposed to CTMA, the stiffness of the cells increased by a factor of 3 (Figure 6C), leading to more rigid cells compared to the control, which is consistent with the expected mode of action of QACs. This was not the case for the cells exposed to BAC, as such an increase in the Young modulus was not observed.

Interestingly, the bacterial surface adhesion properties, measured as the pulling force exerted by the membrane matrix towards an uncoated-silicon probe, revealed a strong decrease when the bacteria were treated with BAC, whereas in the case of CTMA an increase in the unspecific adhesion properties was registered (Figure 6B). Adhesion properties of a bacterial cell are also linked with their ability to create biofilms (58). $P$. aeruginosa is known to form biofilms and to use biofilms as a defense against different chemicals. It was previously observed that BAC inhibits the biofilm formation of $P$. aeruginosa, which could explain the observed decrease in the adhesion properties when exposed to BAC (59). In contrast, in this study, the adaptation of $P$. aeruginosa to CTMA was associated with modifications of the bacterial membrane and an increase in adhesion properties, which could enhance the biofilm formation. These two mechanisms are consistent with previous observations when increasing concentrations of QACs were used, either with biofilm as a resistance mechanism (60) or with an exposure to BAC preventing the biofilm formation (59).

Even though CTMA and BAC modified the biomechanical properties of $P$. aeruginosa in a significantly different way, they both strongly affect the cells by modifying their morphological properties and hence the bacterial interaction with the external environment. Besides, the outer membrane roughness significantly changed by increasing the numbers and the height of "hills" and "valleys" of the external lipid bilayer and the lipo-poly-saccharides matrix. Potentially, the measured roughness could be a 
consequence of a deeper and stronger modification at a lower membrane level, mainly affecting the inner membrane.

\subsection{Practical implications: exposure to commercial disinfection agents}

Two commercial disinfection agents, currently used in the health care context for medical instrument pre-cleaning/disinfection and surface cleaning detergent were tested to compare their effects with single compounds (BAC and CTMA). Exposure to both disinfection agents, in their commercial forms, led to an adaptation of the exposed populations. The increase of the MIC, after 10 cycles, was similar for both products, an average factor of 1.7 for Deconex ${ }^{\circledR} 53$ PLUS and 1.75 for Incidin ${ }^{\circledR}$ PLUS. Both commercial products led to adapted populations of $P$. aeruginosa similarly to QACs. The adaptation is stable during the 5 cycles in absence of the product, which is similar to BAC but different to CTMA. Exposure to QAC-containing commercial products also yielded an increased tolerance to the two pure QACs tested, but no changes in the antibiotic resistances.

This result is relevant for cases where bacterial populations are in contact with residual concentrations of the product. Due to a widespread application of QACs in hospitals, some uses in cleaning and discharge of wastewaters or other point sources may contain relatively high sub-inhibitory concentrations of disinfection agents, which may lead to development of increased MICs in the bacterial communities. Depending on the applied QAC-containing disinfection agents, it may also lead to morphological changes and adhesion and biofilm formation potentials. In contrast to these high subinhibitory concentration scenarios, the exposure to the $\mu \mathrm{g} / \mathrm{L}$ levels of QACs present in municipal wastewater treatment plants may not lead to changes in the MICs.

\section{Conclusion}


559 This study showed for two selected QACs and two commercial disinfection agents that $560 P$. aeruginosa cells can adapt to these treatments, when exposed to approximately

561 $90 \%$ of the MIC. This was exemplified by an increase of the MICs by a maximum factor of 1.45 for CTMA, 1.9 for BAC, 1.7 for Deconex ${ }^{\circledR} 53$ PLUS and 1.75 for Incidin ${ }^{\circledR}$ PLUS. When exposed to a lower concentration (approximately $50 \%$ of MIC), strains exposed to BAC showed a slight adaptation to the product in one replicate. The slight increase observed upon exposure to $50 \%$ of the MIC, may suggest that adaptation is also possible at smaller concentrations, but longer exposure times are necessary. Moreover, not only, the MIC for the QAC to which the bacteria were exposed was increased but also the MIC for the other selected QAC was increased, which means that there is cross-resistance between the two selected QACs. The increase in the resistance to the compounds can be a result of an increase of the stiffness as shown by the AFM results for CTMA. However, the increase in resistance observed when exposed to BAC, is likely caused by a different mechanism, as no increase in the stiffness was observed. Differences were also observed in the adhesion properties following exposure and would require further investigation especially on the biofilm formation potential after exposure to sub-inhibitory concentrations of QACs. The roughness, was increased when exposed to both QACs, confirming that QACs are affecting the membrane and the observed increase might be the consequence of changes at the inner membrane level. The differences observed in the nanomechanical properties of the membrane are also consistent with the differences observed in the resistance evolution following exposure. This may indicate that different or slightly different mechanisms are involved with the different QACs. In contrast, no significant change of the QAC pre-treated bacteria was observed regarding the resistance to antibiotics in this experimental setup based on the EUCAST 
584 interpretational scheme. This result seems to exclude the spread of antibiotic resistant

$585 P$. aeruginosa in the environment following exposure to constant sub-inhibitory 586 concentrations of QACs. The effects obtained with two commercial disinfections 587 agents (containing a QAC or glucoprotamin) were similar to results obtained with 588 QACs.

\section{Acknowledgments}

591 Funding of this project by the Swiss Confederation represented by the Federal Office 592 for the Environment FOEN 3003 Bern (15.0023.KP/P214-1092), EPFL are 593 acknowledged for M.V., M.B., F.B., U.v.G. Fundings by the Swiss National Grants 594 200021-144321,407240_167137, CRSII5_173863, the Gebert Rüf Stiftung 595 GRS-024/14 and NASA NNH16ZDA001N-CLDTCH are acknowledged for L.V, G.D 596 and S.K. We also would like to thank Myriam K.S. Ballo (EPFL), Dessislava Savova 597 Bianchi (university center of legal medicine (CUMRL)), Virginie Bachmann (EPFL) and 598 Caroline Gachet Aquillon (EPFL) for their technical assistance during this project. 
600

601

602

603

604

605

606

607

608

609

610

611

612

613

614

615

616

617

618

619

620

621

622

References

1. Hegstad K, Langsrud S, Lunestad BT, Scheie AA, Sunde M, Yazdankhah SP. Does the Wide Use of Quaternary Ammonium Compounds Enhance the Selection and Spread of Antimicrobial Resistance and Thus Threaten Our Health? Microb Drug Resist [Internet]. 2010;16(2):91-104. Available from: http://online.liebertpub.com/doi/abs/10.1089/mdr.2009.0120

2. Sanidad KZ, Yang H, Wang W, Ozay El, Yang J, Gu M, et al. Effects of consumer antimicrobials benzalkonium chloride, benzethonium chloride, and chloroxylenol on colonic inflammation and colitis-associated colon tumorigenesis in mice. Toxicol Sci. 2018;163(2):490-9.

3. Buffet-Bataillon S, Tattevin P, Bonnaure-Mallet M, Jolivet-Gougeon A. Emergence of resistance to antibacterial agents: The role of quaternary ammonium compounds - A critical review. Int J Antimicrob Agents [Internet]. 2012;39(5):381-9. Available from:

http://dx.doi.org/10.1016/j.jiantimicag.2012.01.011

4. Gerba CP. Quaternary Ammonium Biocides: Efficacy in Application. Müller V, editor. Appl Environ Microbiol [Internet]. 2015 Jan 15 [cited 2018 May 4];81(2):464-9. Available from: http://aem.asm.org/content/81/2/464.full.pdf

5. Jennings MC, Minbiole KPC, Wuest WM. Quaternary Ammonium Compounds: An Antimicrobial Mainstay and Platform for Innovation to Address Bacterial Resistance. ACS Infect Dis. 2016;1(7):288-303.

6. Kümmerer K, Eitel A, Braun U, Hubner P, Daschner F, Mascart G, et al. Analysis of benzalkonium chloride in the effluent from European hospitals by 
solid-phase extraction and high-performance liquid chromatography with postcolumn ion-pairing and fluorescence detection. J Chromatogr A. 1997;774(12):281-6.

7. Boyd GR, Palmeri JM, Zhang S, Grimm DA. Pharmaceuticals and personal care products (PPCPs) and endocrine disrupting chemicals (EDCs) in stormwater canals and Bayou St. John in New Orleans, Louisiana, USA. Sci Total Environ. 2004;333(1-3):137-48.

8. Fatta-Kassinos D. K. Kümmerer, Pharmaceuticals in the environment: sources, fate, effects and risks. Environ Sci Pollut Res [Internet]. 2010 Feb 13;17(2):519-21. Available from: http://link.springer.com/10.1007/s11356-0090276-4

9. Verlicchi P, Galletti A, Petrovic M, BarcelÓ D. Hospital effluents as a source of emerging pollutants: An overview of micropollutants and sustainable treatment options. J Hydrol [Internet]. 2010 [cited 2017 Oct 26];389(3-4):416-28. Available from: http://www.sciencedirect.com/science/article/pii/S0022169410003409

10. Tezel U, Pavlostathis SG. Quaternary ammonium disinfectants: microbial adaptation, degradation and ecology. Curr Opin Biotechnol [Internet]. 2015 Jun;33(Mic):296-304. Available from: http://dx.doi.org/10.1016/j.copbio.2015.03.018

11. Zhang C, Cui F, Zeng G ming, Jiang M, Yang Z zhu, Yu Z gang, et al. Quaternary ammonium compounds (QACs): A review on occurrence, fate and toxicity in the environment. Sci Total Environ [Internet]. 2015;518-519:352-62. Available from: http://dx.doi.org/10.1016/j.scitotenv.2015.03.007 
12. Margot J, Rossi L, Barry DA, Holliger C. A review of the fate of micropollutants in wastewater treatment plants. Wiley Interdiscip Rev Water [Internet]. 2015 Sep;2(5):457-87. Available from: http://doi.wiley.com/10.1002/wat2.1090

13. Kümmerer K. Drugs in the environment: Emission of drugs, diagnostic aids and disinfectants into wastewater by hospitals in relation to other sources - A review. Chemosphere. 2001;45(6-7):957-69.

14. Kummerer K. Resistance in the environment. J Antimicrob Chemother [Internet]. 2004 Jul 1 [cited 2016 Aug 8];54(2):311-20. Available from: https://academic.oup.com/jac/article-lookup/doi/10.1093/jac/dkh325

15. Lindström A, Buerge IJ, Poiger T, Bergqvist PA, Müller MD, Buser HR. Occurrence and environmental behavior of the bactericide triclosan and its methyl derivative in surface waters and in wastewater. Environ Sci Technol. 2002;36(11):2322-9.

16. Ash RJ, Iverson JL. Antibiotic and disinfectant resistant bacteria in rivers of the United States. Proc 4th Int Conf Pharm Endocr Disrupting Chem Water. $2004 ; 1-7$.

17. Ternes TA, Joss A, Siegrist H. Peer Reviewed: Scrutinizing Pharmaceuticals and Personal Care Products in Wastewater Treatment. Environ Sci Technol [Internet]. 2004 Oct 15;38(20):392A-399A. Available from: http://dx.doi.org/10.1021/es040639t

18. Orias F, Perrodin Y. Characterisation of the ecotoxicity of hospital effluents: A review. Sci Total Environ. 2013;454-455:250-76.

19. Russell AD. Mechanisms of bacterial resistance to biocides. Int Biodeterior 

Biodegradation [Internet]. 1995 [cited 2016 Aug 5];36(3-4):247-65. Available from: http://www.sciencedirect.com/science/article/pii/0964830595000569

20. Walsh SE, Maillard JY, Russel AD, Catrenich CE, Charbonneau AL, Bartolo RG. Activity and Mechanism of Action of Selected Biocidal Agents on Gram positive and -negative Bacteria. J Appl Microbiol. 2003;94:240-7.

21. Martínez-Carballo E, Sitka A, González-Barreiro C, Kreuzinger N, Fürhacker M, Scharf S, et al. Determination of selected quaternary ammonium compounds by liquid chromatography with mass spectrometry. Part I. Application to surface, waste and indirect discharge water samples in Austria. Environ Pollut. 2007;145(2):489-96.

22. Ismail ZZ, Tezel U, Pavlostathis SG. Sorption of quaternary ammonium compounds to municipal sludge. Water Res. 2010;

23. Sarkar B, Megharaj M, Xi Y, Krishnamurti GSR, Naidu R. Sorption of quaternary ammonium compounds in soils: Implications to the soil microbial activities. J Hazard Mater. 2010;

24. Oz T, Guvenek A, Yildiz S, Karaboga E, Tamer YT, Mumcuyan N, et al. Strength of selection pressure is an important parameter contributing to the complexity of antibiotic resistance evolution. Mol Biol Evol. 2014;31(9):2387401.

25. Moen B, Rudi K, Bore E, Langsrud S. Subminimal inhibitory concentrations of the disinfectant benzalkonium chloride select for a tolerant subpopulation of Escherichia coli with inheritable characteristics. Int J Mol Sci. 2012;13(4):410123. 
693

694

695

696

697

698

699

700

701

702

703

704

705

706

707

708

709

710

711

712

713

714

715

716

26. Sandegren L. Selection of antibiotic resistance at very low antibiotic concentrations. Ups J Med Sci [Internet]. 2014;119(2):103-7. Available from: http://www.tandfonline.com/doi/full/10.3109/03009734.2014.904457

27. Chapman JS. Biocide resistance mechanisms. Int Biodeterior Biodegrad [Internet]. 2003 [cited 2016 Aug 8];51(2):133-8. Available from: www.elsevier.com/locate/ibiod

28. Mc Cay PH, Ocampo-Sosa AA, Fleming GTA. Effect of subinhibitory concentrations of benzalkonium chloride on the competitiveness of Pseudomonas aeruginosa grown in continuous culture. Microbiology [Internet]. 2010 Jan 1 [cited 2016 Aug 24];156(1):30-8. Available from: http://mic.microbiologyresearch.org/content/journal/micro/10.1099/mic.0.02975 $1-0$

29. Buffet-Bataillon S, Tattevin P, Maillard J-Y, Bonnaure-Mallet M, JolivetGougeon A. Efflux pump induction by quaternary ammonium compounds and fluoroquinolone resistance in bacteria. Future Microbiol [Internet]. 2016 Jan [cited $2017 \mathrm{Jul} 13] ; 11(1): 81-92$. Available from: http://dx.doi.org/10.2217/fmb.15.131

30. Thomas L, Maillard J-Y, Lambert RJW, Russell AD. Development of resistance to chlorhexidine diacetate in Pseudomonas aeruginosa and the effect of a "residual" concentration. J Hosp Infect [Internet]. 2000 [cited 2016 Aug 23];46(4):297-303. Available from: http://www.idealibrary.com

31. Loughlin MF, Jones M V., Lambert PA. Pseudomonas aeruginosa cells adapted to benzalkonium chloride show resistance to other membrane-active agents but not to clinically relevant antibiotics. J Antimicrob Chemother 
[Internet]. 2002 Apr 1 [cited 2017 Jul 13];49(4):631-9. Available from: https://academic.oup.com/jac/article-lookup/doi/10.1093/jac/49.4.631

32. Joynson JA, Forbes B, Lambert RJW. Adaptive resistance to benzalkonium chloride, amikacin and tobramycin: The effect on susceptibility to other antimicrobials. J Appl Microbiol. 2002;93(1):96-107.

33. Tabata A, Maeda T, Nagamune H, Kourai H. Characterization of Pseudomonas aeruginosa Resistant to a Quaternary Ammonium Compound. Biocontrol Sci [Internet]. 2002;7(3):147-53. Available from:

http://joi.jlc.jst.go.jp/JST.Journalarchive/bio1996/7.147?from=CrossRef

34. Thomas L, Russell AD, Maillard JY. Antimicrobial activity of chlorhexidine diacetate and benzalkonium chloride against Pseudomonas aeruginosa and its response to biocide residues. J Appl Microbiol. 2005;98(3):533-43.

35. Kim M, Weigand MR, Oh S, Hatt JK, Krishnan R, Tezel U, et al. Widely Used Benzalkonium Chloride Disinfectants Can Promote Antibiotic Resistance. Dozois CM, editor. Appl Environ Microbiol [Internet]. 2018 Jun 29;84(17):1-14. Available from: http://aem.asm.org/lookup/doi/10.1128/AEM.01201-18

36. McDonnell G, Russell AD. Antiseptics and Disinfectants : Activity, Action , and Resistance. Clin Microbiol Rev. 1999;12(1):147-79.

37. Bert F, Maubec E, Bruneau B, Berry P, Lambert-Zechovsky N. Multi-resistant Pseudomonas aeruginosa outbreak associated with contaminated tap water in a neurosurgery intensive care unit. J Hosp Infect [Internet]. 1998 May;39(1):53-62. Available from: https://linkinghub.elsevier.com/retrieve/pii/S0195670198902432 
38. Kerr KG, Snelling AM. Pseudomonas aeruginosa: a formidable and everpresent adversary. J Hosp Infect [Internet]. 2009;73(4):338-44. Available from: http://dx.doi.org/10.1016/j.jhin.2009.04.020

39. Mena KD, Gerba CP. Risk Assessment of Pseudomonas aeruginosa in Water. In: Reviews of Environmental Contamination and Toxicology [Internet]. 2009. p. 71-115. Available from: http://link.springer.com/10.1007/978-1-4419-0032-6_3

40. Loveday HP, Wilson JA, Kerr K, Pitchers R, Walker JT, Browne J. Association between healthcare water systems and Pseudomonas aeruginosa infections: A rapid systematic review. J Hosp Infect [Internet]. 2014;86(1):7-15. Available from: http://dx.doi.org/10.1016/j.jhin.2013.09.010

41. Tyski S, Grzybowska W, Grzeszczuk S, Leszczynski P, Staniszewska M, Röhm-Rodowald E, et al. Antimicrobial Activity of Glucoprotamin-Containing Disinfectants. Polish J Microbiol. 2009;58(4):347-53.

42. Chojecka A, Wiercińska O, Röhm-rodowald E. Glucoprotamin antimicrobial activity against selected standard antibiotic-resistant bacteria and reference strains used in the assessment of disinfection efficacy. Natl Inst Public Heal Natl Inst Hyg. 2015;66(3):281-8.

43. Braga PC, Ricci D, Braga PC, Ricci D. Atomic Force Microscopy : Application to Investigation of Escherichia coli Morphology before and after Exposure to Cefodizime. Antimicrob Agents Chemother. 1998;42(1):1-6.

44. Dufrêne YF. Application of atomic force microscopy to microbial surfaces : from reconstituted cell surface layers to living cells. Micron. 2001;32:153-65.

45. Longo G, Kasas S. Effects of antibacterial agents and drugs monitored by 
atomic force microscopy. Wiley Interdiscip Rev Nanomedicine Nanobiotechnology [Internet]. 2014 May [cited 2016 Aug 3];6(3):230-44. Available from: http://doi.wiley.com/10.1002/wnan.1258

46. Formosa C, Grare M, Jauvert E, Coutable A, Regnouf-de-Vains JB, Mourer M, et al. Nanoscale analysis of the effects of antibiotics and CX1 on a Pseudomonas aeruginosa multidrug-resistant strain. Sci Rep [Internet]. 2012 Dec 14 [cited 2018 Mar 6];2(1):575. Available from: https://www.nature.com/articles/srep00575.pdf

47. Eskandarian HA, Odermatt PD, Ven JXY, Hannebelle MTM, Nievergelt AP, Dhar N, et al. Division site selection linked to inherited cell surface wave troughs in mycobacteria. Nat Microbiol [Internet]. 2017 Sep 26;2(9):17094. Available from: http://www.nature.com/articles/nmicrobiol201794

48. Jennings MC, Buttaro BA, Minbiole KPC, Wuest WM. Bioorganic Investigation of Multicationic Antimicrobials to Combat QAC-Resistant Staphylococcus aureus. ACS Infect Dis. 2016;1(7):304-9.

49. Wiegand I, Hilpert K, Hancock REW. Agar and broth dilution methods to determine the minimal inhibitory concentration (MIC) of antimicrobial substances. Nat protoc [Internet]. 2008 [cited 2016 Sep 6];3(2):163-75. Available from: http://www.ncbi.nlm.nih.gov/pubmed/18274517

50. Andrews JM. Determination of minimum inhibitory concentrations. J Antimicrob Chemother. 2001;48 Suppl 1:5-16.

51. EUCAST, ESCMID. Determination of minimum inhibitory concentrations (MICs) of antibacterial agents by agar dilution. Clin Microbiol Infect [Internet]. 2000;6(9):509-15. Available from: http://dx.doi.org/10.1046/j.1469- 
52. Bates D, Mächler M, Bolker B, Walker S. Fitting Linear Mixed-Effects Models Using Ime4. J Stat Softw [Internet]. 2015;67(1). Available from: http://arxiv.org/abs/1406.5823

53. Shaffer J. Multiple Hypothesis Testing. Annu Rev Psychol. 1995;46(1):561-84.

54. Tandukar M, Oh S, Tezel U, Konstantinidis KT, Pavlostathis SG. Long-Term Exposure to Benzalkonium Chloride Disinfectants Results in Change of Microbial Community Structure and Increased Antimicrobial Resistance. Environ Sci Technol [Internet]. 2013 Sep 3;47(17):9730-8. Available from: http://pubs.acs.org/doi/10.1021/es401507k

55. Formosa C, Grare M, Duval RE, Dague E. Nanoscale effects of antibiotics on P. aeruginosa. Nanomedicine Nanotechnology, Biol Med [Internet]. 2012 Jan;8(1):12-6. Available from: http://dx.doi.org/10.1016/j.nano.2011.09.009

56. Mortensen NP, Fowlkes JD, Sullivan CJ, Allison DP, Larsen NB, Molin S, et al. Effects of Colistin on Surface Ultrastructure and Nanomechanics of Pseudomonas aeruginosa Cells. Langmuir [Internet]. 2009 Mar 17;25(6):372833. Available from: https://pubs.acs.org/doi/10.1021/la803898g

57. Gilbert P, Moore LE. Cationic antiseptics: Diversity of action under a common epithet. J Appl Microbiol. 2005;99(4):703-15.

58. Zabielska J, Kunicka-Styczyńska A, Otlewska A. Adhesive and hydrophobic properties of Pseudomonas aeruginosa and Pseudomonas cedrina associated with cosmetics. Ecol Quest [Internet]. 2018 Feb 10;28:41. Available from: http://apcz.umk.pl/czasopisma/index.php/EQ/article/view/EQ.2017.037 
810

811

812

813

814

815

816

817

59. Houari A, Di Martino P. Effect of chlorhexidine and benzalkonium chloride on bacterial biofilm formation. Lett Appl Microbiol. 2007;45(6):652-6.

60. McBain AJ, Ledder RG, Moore LE, Catrenich CE, Gilbert P. Effects of Quaternary-Ammonium-Based Formulations on Bacterial Community Dynamics and Antimicrobial Susceptibility. Appl Environ Microbiol [Internet]. 2004 Jun 1;70(6):3449-56. Available from:

http://dx.doi.org/10.1016/j.copbio.2015.03.018 


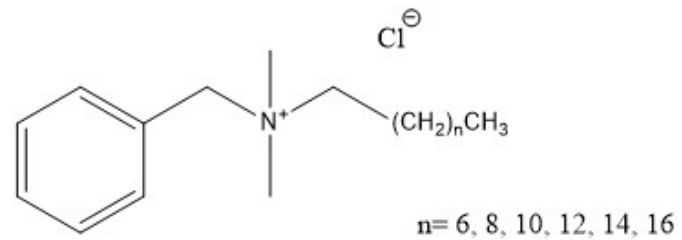

A

819

820

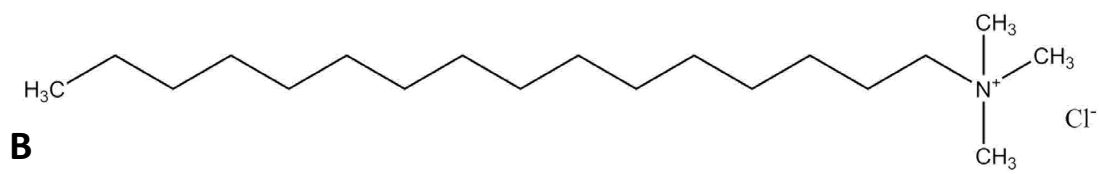

821 Figure 1. Chemical structures of quaternary ammonium compounds. A. Benzalkonium

822 chloride (BAC); B. Cetyltrimethylammonium chloride (CTMA)

823 


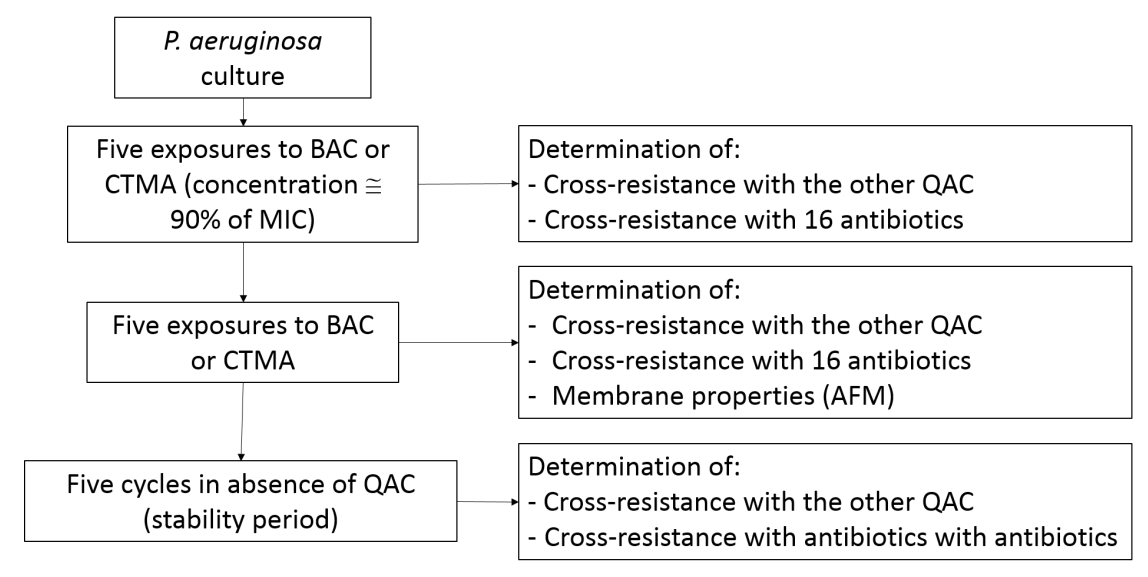

825 Figure 2. Summary of the experiments performed with $P$. aeruginosa and the two 826 QACs. Tubes of MHB with a sub-inhibitory concentration of QAC (either BAC or CTMA)

827 were inoculated with a pure $P$. aeruginosa culture. After five and ten exposure cycles, 828 cross-resistance to the other QAC and to antibiotics was determined. Additionally, after 82910 cycles, populations were analyzed by AFM. After exposure to QACs, populations 830 were sub-cultured for five additional cycles in QAC-free MHB and cross-resistance to 831 the other QAC and antibiotics determined. 

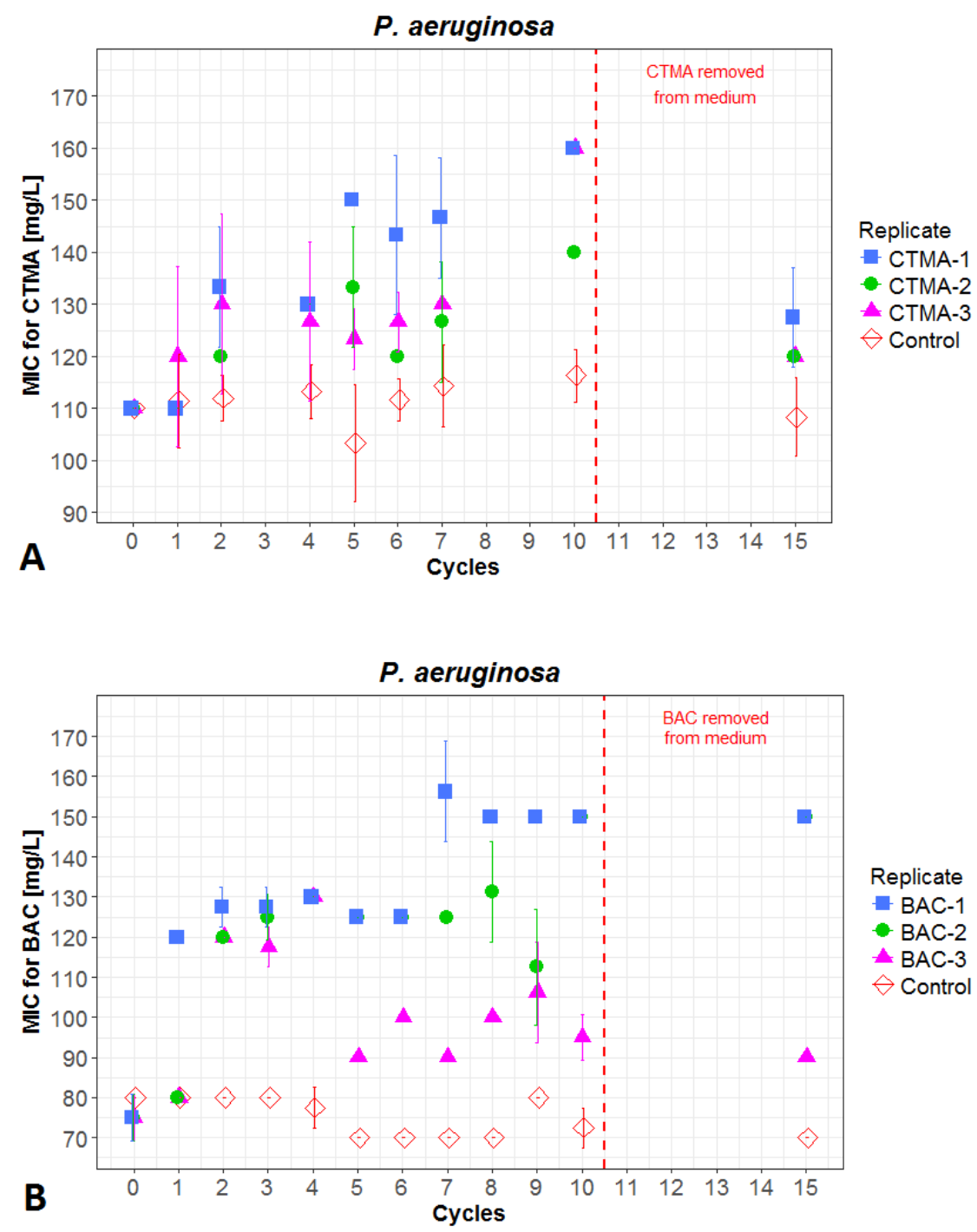

Figure 3. Evolution of the MICs of $\boldsymbol{P}$. aeruginosa when exposed to sub-inhibitory concentrations of (A) CTMA (95 mg l-1) or (B) BAC (70 mg l-1). The effect of absence of the QACs after 10 cycles on the MICs is also shown. Each exposure cycle lasted 48

837 hours. Each point is the average of at least 4 technical measurements, error bars 838 represent the standard deviations. A. MIC evolution of three $P$. aeruginosa populations exposed to CTMA (CTMA-1/2/3) and one control (not exposed to CTMA) as a function of the exposure cycles. B. MIC evolution of three $P$. aeruginosa populations exposed to $\mathrm{BAC}(\mathrm{BAC}-1 / 2 / 3)$ and one control (not exposed to $\mathrm{BAC}$ ) as a function of the

842 exposure cycles. 

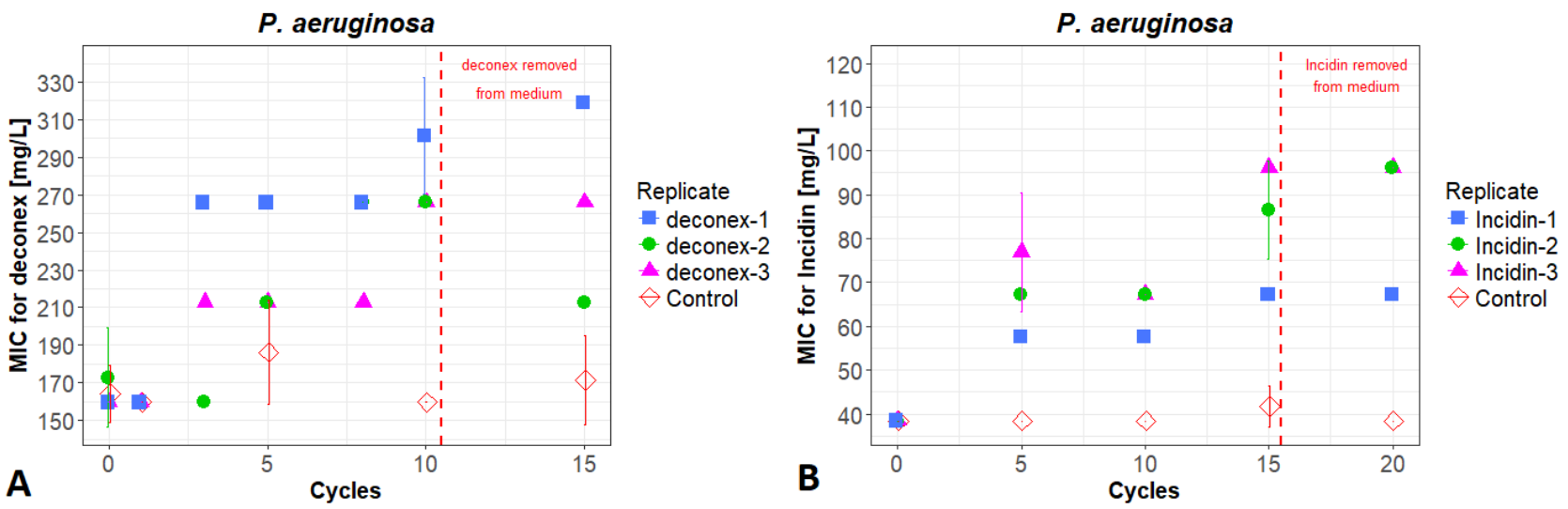

845 Figure 4. Evolution of the $P$. aeruginosa's MIC when exposed to (A) Deconex ${ }^{\circledR} 53$

846 PLUS or (B) Incidin ${ }^{\circledR}$ PLUS. Three P. aeruginosa populations (exposed to Deconex ${ }^{\circledR}$

84753 PLUS (A) or Incidin ${ }^{\circledR}$ PLUS (B)) and one control (not exposed to Deconex ${ }^{\circledR} 53$ PLUS

848 or Incidin ${ }^{\circledR}$ PLUS) as a function of the exposure cycles. Each cycle lasted 24 hours.

849 Each point is the average of at least 4 technical measurements and error bars

850 represent the standard deviations. 

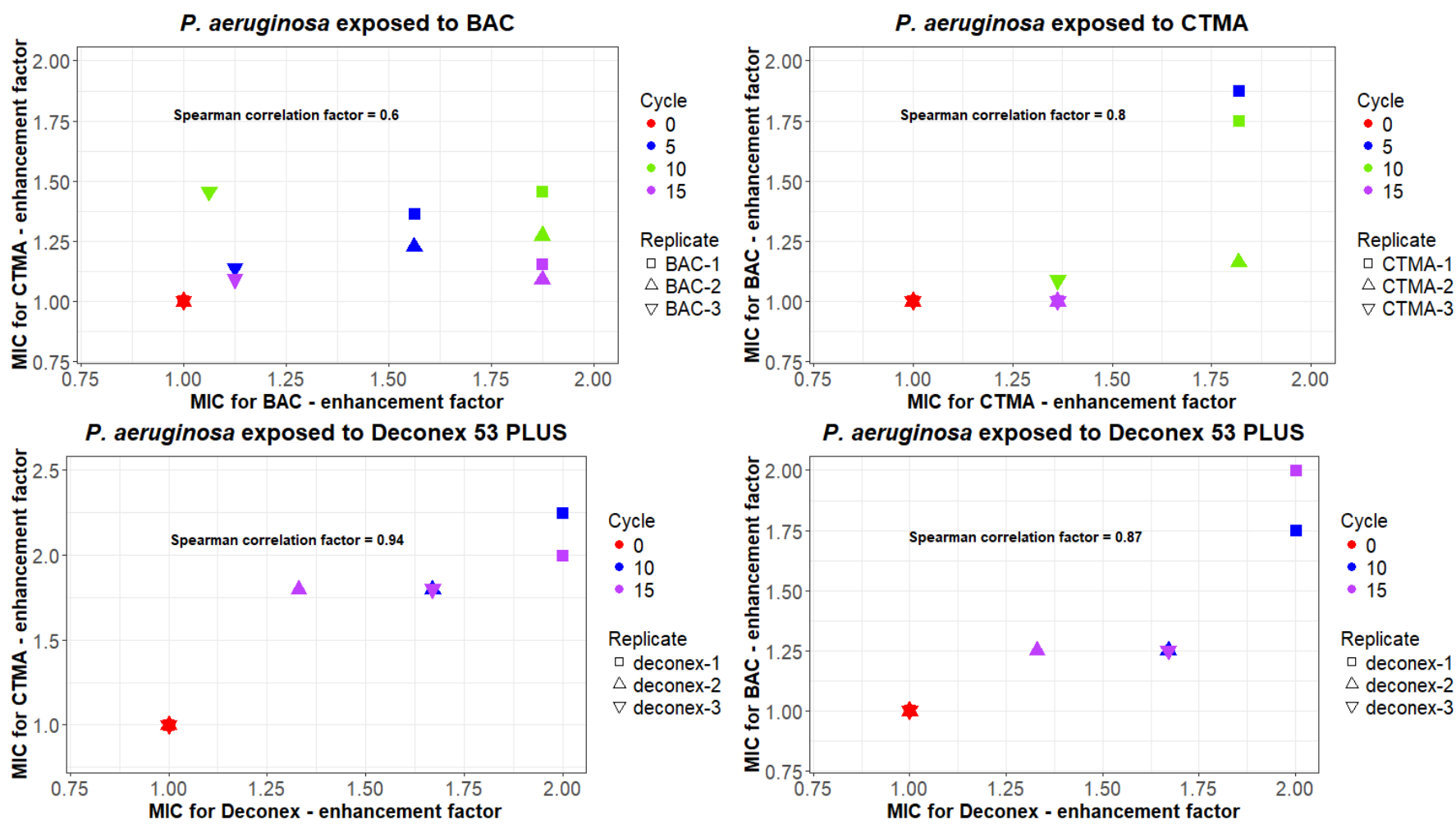

853 Figure 5. Correlation factors for the cross-resistance experiment. A. Correlation

854 between the enhancement factor of the MIC for CTMA and the MIC for BAC when

855 exposed to CTMA. B. Correlation between the enhancement factor of the MIC for BAC

856 and the MIC for CTMA when exposed to CTMA. C. Correlation between the

857 enhancement factor of the MIC for Deconex ${ }^{\circledR} 53$ PLUS and the MIC for BAC when

858 exposed to Deconex ${ }^{\circledR} 53$ PLUS. D. Correlation between the enhancement factor of the

859 MIC for Deconex ${ }^{\circledR} 53$ PLUS and the MIC for CTMA when exposed to Deconex ${ }^{\circledR} 53$ PLUS. 

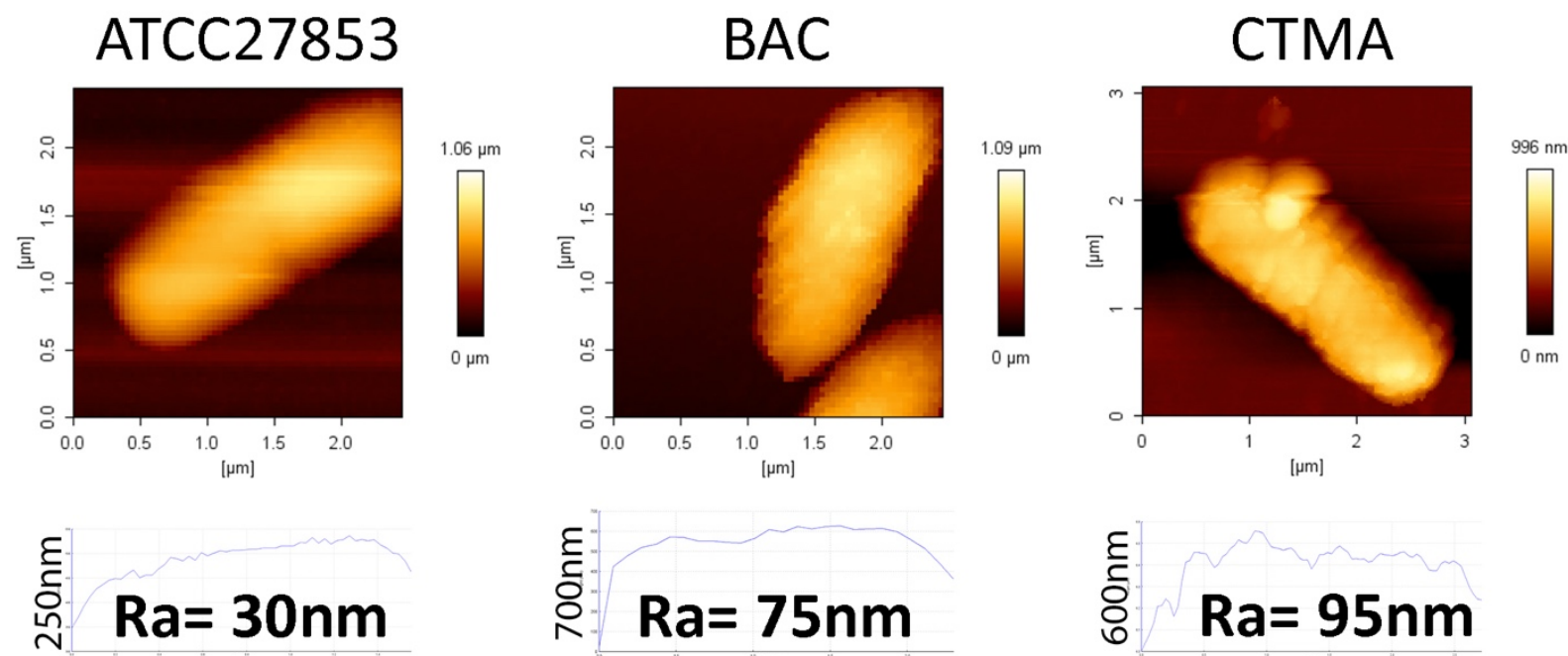

A
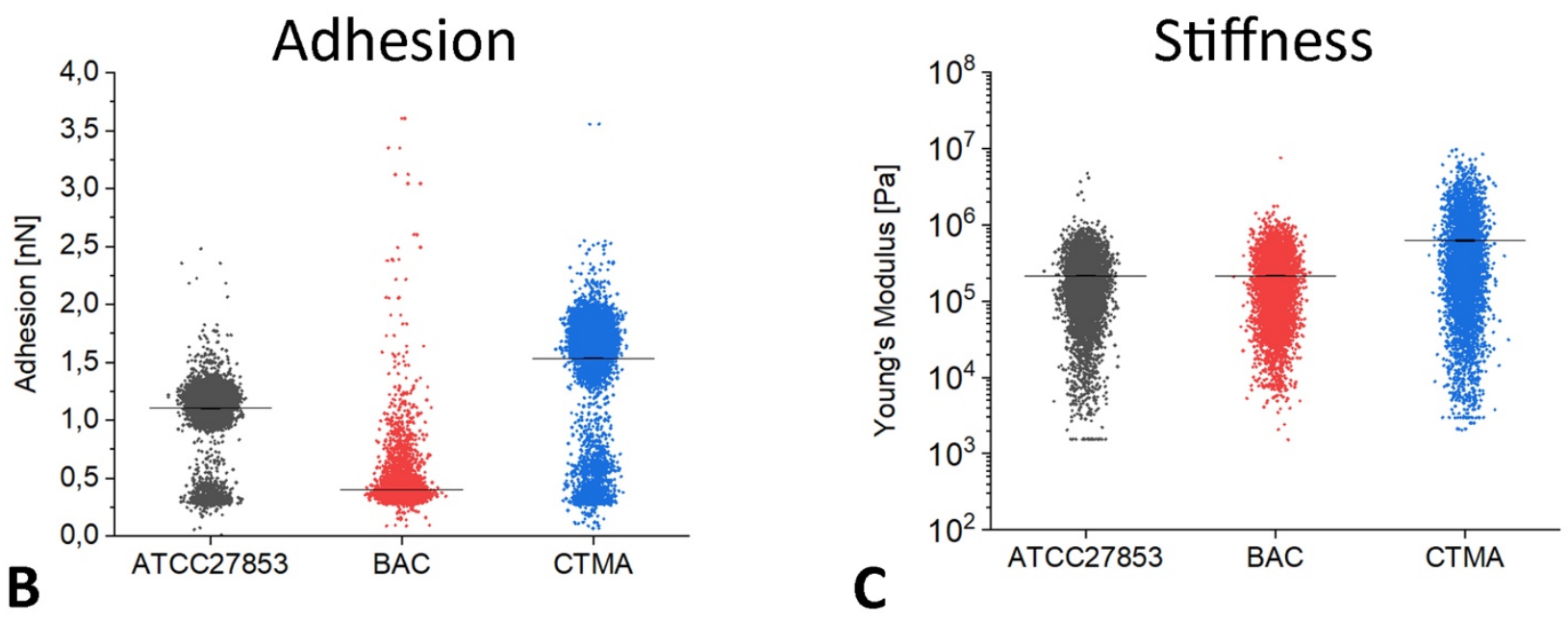

Figure 6. AFM investigation of the mechanical properties of $P$. aeruginosa. A:

Two representative images are shown for each tested QAC (BAC, middle and CTMA, right) and one without treatment (ATCC 27583). Below, a typical profile for the outer membrane roughness $(\mathrm{Ra})$ is plotted as its average value. The $\mathrm{Y}$-axes scales differ significantly and from left to right are as follows: $250 \mathrm{~nm}, 700 \mathrm{~nm}$ and $600 \mathrm{~nm}$, respectively. Both treatments with QACs significantly changed the membrane average roughness as reported in numbers in each plot: 30, 75 and $95 \mathrm{~nm}$, respectively. was considered significant $(n=15)$.

B: Adhesion plot distribution. Each dot represents 
871 a single measured pixel from a bacteria cell. C: Stiffness plot distribution. Each dot 872 represents a single measured pixel from a bacteria cell. 